\title{
A inexigibilidade de conduta diversa como causa supralegal de exclusão da culpabilidade e sua submissão à apreciação no tribunal do júri
}

\author{
Susana Broglia Feitosa de Lacerda ${ }^{1}$
}

\section{Resumo}

Inexigibilidade de conduta diversa. Possibilidade de submissão à apreciação do Conselho de Sentença, ainda que seja causa supralegal de exclusão da culpabilidade. Entendimento baseado na doutrina contemporânea e na jurisprudência mais recente dos Tribunais Superiores. A quesitação da referida tese a ser apreciada pelo Conselho de Sentença deve conter matéria fática e não conceitos jurídicos.

Palavras-Chave: Inexigibilidade de conduta diversa; Causa supralegal; Júri.

\section{Introdução}

Com o advento do reforma penal de 1984, não há dúvidas acerca da obrigatoriedade da quesitação da tese da inexigibilidade de conduta diversa como causa supralegal da exclusão da culpabilidade no Tribunal do Júri, por óbvio, desde que tal tese tenha sido ventilada pela defesa em plenário, buscando-se assim obediência ao princípio constitucional da plenitude de defesa (CF, art. 5ㅇ, XXXVIII, $a$ ).

Referida matéria ainda é geradora de grande discussão, por inúmeros fatores, por haver aqueles que ainda sustentam o não cabimento da quesitação face ao disposto no artigo 484, inciso III, do Código de Processo Penal, ou em razão da forma que a causa supralegal é submetida à votação ou ainda devido ao fato de favorecer a impunidade, pelo seu uso indiscriminado.

A escolha do assunto deve-se ao fato de que o estudo e a pesquisa sobre a matéria optada, além do enriquecimento intelectual, surgiram a partir de reflexões necessárias para solucionar dificuldades oriundas da atividade profissional exercida (Promotora de Justiça com atribuições no Tribunal do Júri da Comarca de Londrina).

Embora haja considerável contribuição doutrinária e jurisprudencial acerca da inexigibilidade de conduta diversa como causa supralegal da exclusão da culpabilidade e a

\footnotetext{
1 Promotora de Justiça da Comarca de Londrina/Pr com atribuições exclusivamente nos crimes dolosos contra a vida - do inquérito policial ao plenário.
} 
possibilidade de quesitação no Tribunal do Júri, segundo o ponto de vista defendido, aludida tese defensiva muitas vezes não é reconhecida e apreciada com a preparação necessária pelos operadores do direito, interferindo indevidamente no veredicto proferido pelos juízes da causa, ou seja, os jurados que são juízes leigos.

Feitas essas considerações, espera-se tenha tido a dedicação, a inspiração e a criatividade necessárias para bem tratar e explorar o tema, contribuindo, de alguma forma, para a elucidação desse assunto que revela ser tão palpitante.

\section{Do cabimento da submissão da causa supralegal aos jurados}

A discussão acerca da possibilidade de quesitação no Tribunal do Júri da inexigibilidade de conduta diversa como causa supralegal de exclusão da culpabilidade surge, dentre outros motivos, face à redação do artigo 484, inciso III, do Código de Processo Penal, com redação dada pela Lei no 9.113, de 16.10.1995 dispõe:

Se o réu apresentar, na sua defesa, ou alegar, nos debates qualquer fato ou circunstância que por lei isente de pena ou exclua o crime, ou o desclassifique, o juiz formulará os quesitos correspondentes imediatamente depois dos relativos ao fato principal, inclusive os relativos ao excesso doloso ou culposo quando reconhecida qualquer excludente de ilicitude (grifo nosso).

O aludido artigo, ao dispor sobre a formulação de quesitos, traça os limites legais, ou seja, o questionamento aos jurados só poderá ser feito quanto às causas que por lei isente de pena, ou exclua o crime ou o desclassifique.

Assim, levando-se em consideração que a inexigibilidade de conduta diversa não foi contemplada no Código Penal Brasileiro não poderia ser quesitada.

Há diversos julgados e vários doutrinadores apontando que o artigo 484, inciso III, do Código de Processo Penal, determina a quesitação somente quando ocorrerem as causas que isentem de pena ou excluam o crime, expressamente previstas em lei. Logo, quando houver causa supralegal de ilicitude ou inculpabilidade não pode ser quesitada, vez que, por óbvio, não está prevista no ordenamento jurídico. Por outro lado sustentam, em síntese, que adoção da existência de causas supralegais de exclusão da ilicitude ou da culpabilidade favoreceria a ocorrência da absolvição em situações absurdas, gerando a impunidade dos autores dos delitos dolosos contra a vida. 
A aceitação de tal tese pelo Conselho de Sentença poderia permitir, por exemplo, que um cidadão que vive numa favela, arme-se ilegalmente e "faça justiça com as próprias mãos". Permite-se a barbárie, "o olho por olho, dente por dente", ferindo inclusive a competência constitucional do Tribunal de Júri de julgar, vez que possibilita a vingança, a revanche.

Citando julgados que resumem o posicionamento acima exposto:

O entendimento de que a inexigibilidade de conduta diversa deve ser aceita como causa supralegal de exculpação, com o suprimento de suposta lacuna do ordenamento jurídico positivo pela analogia 'in bonam partem', nunca foi dominante entre nós e não merece consagrado, agora, após reforma legislativa que ensejou a modernização do sistema penal em matéria de dirimentes e no momento em que essa proposta de extensão analógica vem sendo francamente repudiada pela doutrina dos povos cultos.

Se, como se vem demonstrar, não há reconhecer lacunas na lei em matéria de dirimentes, a impor a integração ou extensão do respectivo rol com o socorro da analogia 'in bonam partem', impossível submeter ao Júri quesito versando a inexigibilidade de outra conduta, por não se constituir em "fato ou circunstância que por lei isente de pena ou exclua o crime", como reclama o permissivo do art. 484 , inc. III do CPP. Formulada, não obstante, a pergunta e resultando da resposta inculpação do réu, como ocorreu no caso em debate, nulo julgamento porque não subsumível a absolvição às hipóteses legais (art. 386 do CPP). Cuida-se de nulidade absoluta por incongruência da decisão com o ordenamento jurídico, não sanável pela ausência de protesto oportuno. Expressamente argüida no recurso da acusação, imperativo seu acolhimento. (TJSP, AC 76.681, rel. Dante Busana, j. 6.8.90). - grifo nosso. No mesmo sentido: RT 589/323

No Rio Grande do Sul, de onde parte essa jurisprudência, aresto da lavra do Desembargador Alaor Wiltgens Terra, em que fulmina de nulidade decisão do júri que acolheu a tese da inexigibilidade de conduta diversa, estabelece:

Ademais, tão descabida é a tese, que subverte todo o sistema brasileiro, afirmando a legalidade da morte como sanção, pois a tanto corresponde afirmar a 'inexigibilidade de conduta diversa', vale dizer, nas circunstâncias só cabia matar! Isto é, não cabia apelar para o aparelhamento policial ou judicial existentes (MARREY, Adriano, 2000).

No mesmo sentido, também acórdão do mesmo Tribunal inserto na RJTJRG v. 89/147, relator o Desembargador Paulo David Torres Barcelos:

Não podem os jurados serem questionados sobre a inexigibilidade de outra conduta como causa autônoma extralegal de exclusão de criminalidade depois de terem rejeitado as teses da legítima defesa própria e putativa. $A$ inexigibilidade de 
outra conduta é uma válvula de escape surgida na Alemanha para resolver casos sumamente restritos e reclamo de justiça. Mas somente naqueles casos extremos redutíveis ao estado de necessidade. Sendo assim inconcebível é que sejam os jurados questionados a respeito da inexigibilidade de outra conduta, excludente não amparada na lei, depois de terem negado as excludentes consignadas no Código. Nulidade conseqüente.

Mais recentemente, o Tribunal de Justiça de São Paulo, em v. acórdão relatado pelo Desembargador Dante Busana seguiu essa mesma orientação (Apelação Criminal no 76.6813, de São Bernardo do Campo).

Repise-se que, deixando-se de lado as questões jurídicas, a maior preocupação dos defensores da posição acima explicitada é o desencadeamento de uma impunidade generalizada.

Interessante se faz, nesse momento, transcrever o que afirmaram os ilustres doutrinadores Zaffaroni e Pierangeli (1997, p. 62), em sua obra conjunta, a respeito da "inexigibilidade de outra conduta", como causa supra legal de excludente de culpabilidade:

[...] sobretudo, depois da Segunda Guerra Mundial, quando a inexigibilidade converteu-se em perigoso argumento, com a finalidade de exculpar crimes atrozes, ou, a participação neles, a legislação positiva começou a polir as fórmulas legais, e mesmo os autores alemães foram abandonando a tese da eximente autônoma da exigibilidade de outra conduta, para que a mesma permanecesse apenas como fundamentação genérica de todas as causas de inculpabilidade. Diante da vigente legislação positiva brasileira, e de maneira como temos entendido as hipóteses de inculpabilidade, cremos que se torna totalmente desnecessária a busca de uma eximente autônoma de inexigibilidade de conduta diversa, que pode ter atendido a exigências históricas já superadas, mas cuja adoção, hoje, prejudica toda a sistemática da culpabilidade.

Assim, sustentam que na hipótese da submissão ao Conselho de Sentença do quesito ou dos quesitos relativos à tese da inexigibilidade de outra conduta, a realização de novo júri é inevitável, devido a ocorrência de nulidade absoluta posterior à pronúncia, nos termos do artigo 564, parágrafo único, combinado com o artigo 484, inciso III, ambos do Código de Processo Penal.

De outro lado, a doutrina pátria em sua maioria, reconhece a inexigibilidade como causa supralegal de exclusão da culpabilidade, podendo citar Aníbal Bruno, Assis Toledo, Frederico Marques, José Paulo da Costa Júnior, Guilherme de Souza Nucci. A inexigibilidade de outra conduta está presente em todas as excludentes de culpabilidade, pois os elementos essenciais ao juízo de censura decorrem da premissa fundamental de que a ordem jurídica 
pode exigir do agente comportamento diverso, sendo que a exculpação evidencia a inexigibilidade da prática de outro comportamento e decorre do fato de que o direito penal somente pode exigir do indívíduo o que lhe seja faticamente possível.

Argumentam que dotado das capacidades de entender e querer, sabendo ou podendo alcançar o conhecimento da ilicitude do fato, o homem detém o poder-agir-deacordo com o Direito, pois livre na elaboração e atuação da vontade, e deve, como conseqüência jurídica, motivar a conduta em conformidade com o sentido protetivo da norma. É o que a ordem jurídica lhe exige. Porém, se apesar de possuir sanidade mental que o possibilite entender e querer, e embora consciente de que faça algo juridicamente proibido, mesmo assim realize o fato típico e antijurídico, em razão de fatores externos, dotados de anormalidade, que the retiram a liberdade para poder agir de acordo com a norma, a culpabilidade, terceiro elemento integrante do crime, é excluída.

Numa concepção pura da culpabilidade, em que a exigibilidade de conduta é o real fundamento do juízo de censura, não estando vinculada a conclusões lógicas, mas em valoração do comportamento humano sob as diferentes faces da ética, da filosofia, da moral e do direito, não há como negar-se a supralegalidade da inexigibilidade como exculpante.

Nesse sentido, as assertivas de Bettiol são bastante conclusivas:

O homem rompe sempre rompe o córtex da legalidade formal para referir-se a valores que superam a vicissitude histórica e refogem a qualquer relativismo, em um direito aberto, que se deve reconhecer. A doutrina de não exigibilidade é uma válvula que permite a um sistema de normas respirar em termos humanos.

O artigo 484, inciso III, do Código de Processo Penal, segundo Assis Toledo (2004, p. 216), deve ser lido da seguinte forma: "qualquer fato ou circunstância que, em nosso ordenamento jurídico-penal, exclua a culpabilidade ou a ilicitude".

Assim, a expressão "por lei" integrante do mencionado artigo não pode ser interpretada como restrição à Reforma Penal de 1984, posto que o princípio da culpabilidade foi adotado sem restrições (nullum crimen sine culpa), conforme se verifica através do item 18 da Exposição de Motivos do Ministro Abi-Ackel.

Portanto, a aplicação da sanção penal em hipótese de inexigibilidade de conduta diversa seria um absurdo, pois o agente, segundo critério objetivos e não subjetivos, que 
serão avaliados pelo juiz, levando-se em conta a situação histórica na qual o sujeito age, fez a única coisa que lhe era humanamente possível fazer.

Interpretação diversa ao referido dispositivo importaria, ou seja, deixar de quesitar causa supralegal de exclusão da culpabilidade, implicaria na existência de uma responsabilidade penal objetiva, que foi abolida de nosso sistema penal pela Reforma de 1984.

O acórdão exarado no REsp no 2.492-RS, julgado em 23.05.90, RT 6601358, tendo como relator o então Ministro Francisco de Assis Toledo é emblemática para a matéria em questão.

Sua ementa é a seguinte:

Inexigibilidade de outra conduta. Causa legal e supralegal de exclusão da culpabilidade cuja admissibilidade no Direito brasileiro já não pode ser negada. Júri. Homicídio. Defesa alternativa baseada na alegação de não exigibilidade de conduta diversa. Possibilidade em tese, desde que se apresentem ao Júri quesitos sobre fatos e circunstâncias, não sobre mero conceito jurídico (Quinta Turma, REsp 2492 /RS, j. 23.05.90, RT 6601358).

Do voto do ilustrado Min. Relator são reproduzidas as seguintes e relevantes passagens:

Assim, fora de dúvida é que o art. 484, III, ao obrigar o Juiz a formular quesitos sobre "qualquer fato ou circunstância que por lei isente de pena ou exclua o crime", está endereçado a qualquer fato ou circunstância que exclua a culpabilidade ou a ilicitude

A expressão 'por lei', situada no Código de Processo Penal de 1941, não pode significar restrição à posterior Reforma Penal de 1984, que, como se viu, adotou o princípio da culpabilidade, sem restrições. Antes, deve a ela ajustar-se, tento mais que saber se existe crime ou não, se está excluída ou não a culpabilidade, é questão exclusiva de direito penal material, não de direito processual.

Leio, pois, presentemente o inciso III do art. 484 assim: "qualquer fato ou circunstância que, em nosso ordenamento jurídico-penal, exclua a culpabilidade ou a ilicitude (grifo nosso).

Nessa linha de pensamento, identifico negativo de vigência a esse preceito, por parte do acórdão, quando nega a possibilidade de formulação de quesitos em uma hipótese de isenção de pena ou de exclusão da culpabilidade, produzindo, como resultado, uma responsabilidade penal objetiva, abolida de nosso sistema penal pela Reforma de 1984. Isso implica em enorme antinomia com o sistema penal vigente, proibindo-se o Júri de absolver o réu, na ausência de culpabilidade, ou, o que não é melhor, proibindo-se a defesa de alegar talvez a única tese disponível, no caso, com alguma possibilidade de reconhecimento pelo Conselho de Sentença. A primeira vedação infringe o princípio da culpabilidade; a segunda viola frontalmente o da ampla defesa, assegurado pelo inciso LV do art. 5o da Constituição vigente... (Quinta Turma, REsp 2492 /RS, j. 23.05.90, RT 6601358). 
Assim, a argumentação e fundamentação jurídica trazida no acórdão em questão sepulta qualquer tentativa de obstar a quesitação da tese de inexigibilidade de conduta diversa como causa supralegal de exclusão da culpabilidade, pois tal posicionamento estaria em desacordo com o ordenamento jurídico vigente, devendo, portanto, esta ser a nova leitura do artigo 484, inciso III, do Código de Processo Penal.

\section{Quesitação}

No tocante à quesitação, é imprescindível que o Juiz Presidente do Tribunal do Júri, assim como os demais operadores do Direito tenham consciência e preocupação que aos jurados não pode ser submetida apreciação de conceitos jurídicos, mas sim conceitos fáticos.

É absurdo, como muitas vezes se observa, que o quesito seja redigido da seguinte forma: "O réu Fulano de Tal agiu acobertado pela inexigibilidade de conduta diversa? ou apenas “O réu Fulano de Tal não poderia ter agido de outra forma, senão matar?

O cerne da discussão não é o número de quesitos formulados para apreciação da tese, mas sim o seu conteúdo e momento para votação. Porém, o desmembramento do quesito proporciona aos jurados melhor apreciação do conjunto de circunstâncias que implicariam no reconhecimento da excludente.

No tocante ao momento da quesitação e seu contéudo, acórdão da lavra do Eminente Desembargador José Antônio Hirt Preiss (TJRS - Apelação Criminal no 7001793575/2006 - julgamento 29.03.07), bem resume e auxilia na problemática da quesitação, citando doutrina e jurisprudência sobre o assunto:

Entendo que é aconselhável o quesito único, mas logo depois de questionado o júri sobre autoria e letalidade, porque define, de imediato, pelo acolhimento, ou não, da excludente. A resposta afirmativa afasta a excludente supralegal. Por óbvio, que a resposta negativa define pelo acolhimento e conseqüente absolvição do acusado. 'A figura da inexigibilidade de outra conduta, ou da não exigibilidade de conduta diversa, que é causa que exclui o crime ou causa de exclusão da culpabilidade, pode, representando tese proposta pela defesa técnica para ser decidida pelos jurados, integrar o questionário com posição - e sendo dada atenção à possível presença de outras teses defensivas propostas, alternatividade - imediatamente após os quesitos relativos ao fato principal (inciso III do art. 484 do CPP). A indagação aos jurados, sem versar exclusivamente sobre o nome ou a definição da figura, deve apresentar a descrição das circunstâncias que levaram, no entender da 
defesa técnica, o agente a agir de maneira tratada pelo libelo. Mesmo não estando expressamente prevista em nosso ordenamento jurídico, a não exigibilidade, que exclui a culpabilidade, constitui 'verdadeiro princípio de Direito Penal'.

O quesito deverá indagar se 'ao réu, à frente de circunstâncias consistentes em: (descrevê-las), poderia ser exigida outra conduta?' A resposta negativa define a excludente. Se diversas as circunstâncias concorrentes para o ato do agente em julgamento, diversos quesitos, em desmembramento indagativo sobre a tese defensiva, serão propostos, cada qual descrevendo uma das circunstâncias motivadoras, assim para evitar a complexidade indagativa na formulação de quesito único".76 (76 Op. cit., Nota 495: Merece ser recordado que 'não há necessidade de desdobramento dos quesitos, em séries, se uma só basta para propiciar aos jurados o entendimento seguro das indagações neles contidas, sem qualquer prejuízo para a defesa' (RTJ 130/680), Rel. Min. Sydney Sanches). ... Outros modelos de quesitos: 'era possível ao acusado, por encontrar-se acuado pela vítima (descrever as circunstâncias), conduta diversa da que assumiu?' redação adotada pelo Juiz Cláudio dos Santos, do Tribunal do Júri da Capital; 'Por já conhecer o temperamento da vítima e ter sido antes ofendido, era de se exigir outro comportamento do réu à frente de movimentação da vítima em sua direção?' - redação adotada pelo Juiz Aben Athar Paiva Coutinho, do mesmo Tribunal; 'Seria razoável exigir do réu conduta diversa, diante das circunstâncias que vivenciou, consistente em (descrever)?' - quesito adotado pelo Juiz Guilherme Souza Nucci, do 30 Tribunal do Júri da Capital, representando a resposta afirmativa do acolhimento da tese defensiva) (TOLEDO, 2004, p. 224-225).

Da experiência em plenário, extrai-se a necessidade do desmembramento dos quesitos, a fim de que os jurados possam analisar as circunstâncias fáticas do caso em julgamento minudentemente, assim como o fazem na legítima defesa e outras causas de exclusão da ilicitude ou culpabilidade.

\section{Conclusão}

É irrefutável a possibilidade de submissão ao Conselho de Sentença a tese defensiva da inexibigilidade de conduta diversa como causa supralegal de exclusão da culpabilidade, face ao advento da Reforma Penal de 1984.

Todovia, é imprescindível que seja submetido a apreciação dos jurados matéria de fato, seja em um único quesito, seja desmembrado em vários quesitos e nunca matéria conceitual, possilibitando aos jurados a apreciação fática do caso.

No Tribunal do Júri a submissão da inexigibilidade de conduta diversa como causa supralegal matéria possibilita, e não poucas vezes, a impunidade, pois os jurados nem sempre conseguem perceber que referida tese é uma válvula de escape diante da impossibilidade de argüir as exculpantes previstas na lei, vez que seriam no caso manifestamente incabíveis. 
Aos Tribunais, incluindo o Tribunal do Júri, cabe a tarefa concreta de interpretação e aplicação das normas, a missão de compatibilizar ou preencher as deficiências legislativas, dando resposta a cada caso de acordo com a sua particularidade, podendo servir o princípio da inexigibilidade para a integração do ordenamento jurídico, sendo o reconhecimento de exculpantes não previstas em lei uma necessidade inafastável, tendo em vista que é praticamente impossível determinar-se uma medida-padrão utilizável para aferir a exigibilidade em todos os casos.

Eis o desafio ao Ministério Público, que deve buscar esclarecer aos jurados que a inexigibilidade de outra conduta é de ser admitida em casos excepcionalíssimos e não pode ser argüida para inocentar homicidas pertencentes a gangues, que buscam seus "inimigos" para darem cabo de suas vidas, sob o argumento de cessar a ameaça que vinham sofrendo. Permitir que nessa situação a possibilidade da admissão que não era exigível outra conduta, é autorizar a execução, o "olho por olho, dente por dente".

\section{Referências}

BITENCOURT, Cezar Roberto. Tratado de Direito Penal. Parte geral. 8 ed. São Paulo: Editora Saraiva, 2003.

CAPEZ, Fernando. Curso de Processo Penal. 11. ed. rev. atual. e ampl. São Paulo: Editora Saraiva, 2004.

FERNANDES, Antonio Scarance. Processo Penal Constitucional. 2 ed. rev. atual. e ampl. São Paulo: Editora Revista dos Tribunais, 2000.

MARREY, Adriano et. al. Teoria e Prática do Júri. 4. ed. rev. e ampl. São Paulo: Editora Revista dos Tribunais, 2000.

NUCCI, Guilherme de Souza. Manual de processo penal e execução penal. 3. ed. rev. atual. e ampl. São Paulo: Editora Revista dos Tribunais, 2007.

. Júri: princípios constitucionais. São Paulo: Editora Juarez de Oliveira, 1999.

PORTO, Hermínio Alberto Marques Porto. Julgamento do Tribunal do Júri: questionário. In: TUCCl, Rogério Lauria (Coord.). Tribunal do Júri. Estudo sobre a mais democrática instituição jurídica brasileira. São Paulo: Editora Revista dos Tribunais, 1999. 
SANTOS, Juarez Cirino dos Santos. A Moderna Teoria do Fato Punível. 3 ed. rev. e ampl. Curitiba: Editora Fórum, 2004.

TOLEDO, Francisco de Assis. Culpabilidade e Tribunal do Júri. In: TUCCI, Rogério Lauria (Coord.). Tribunal do Júri. Estudo sobre a mais democrática instituição jurídica brasileira. São Paulo: Editora Revista dos Tribunais, 1999.

. Princípios Básicos de Direito Penal. 5 ed. São Paulo: Editora Saraiva, 2004.

ZAFFARONI, Eugenio Raúl; PIERANGELI, José Henrique. Manual de Direito Penal Brasileiro, parte geral. São Paulo: Editora Revista dos Tribunais, 1997. 